\title{
Individual Differences in Working Memory Abilities in Healthy Adults
}

\author{
R. M. Morais ${ }^{1,3} \cdot$ M. V. Pera $^{1} \cdot$ V. Ladera ${ }^{1} \cdot$ J. Oliveira ${ }^{2} \cdot$ R. García ${ }^{1}$
}

Published online: 13 February 2018

○) Springer Science+Business Media, LLC, part of Springer Nature 2018

\begin{abstract}
The goal of this study was to understand the role of individual characteristics such as age, gender and education of healthy adults on working memory abilities, as conceptualized in the central executive, phonological loop, and visuospatial sketchpad. The sample comprised 302 adults aged from 18 to 65 with different educational backgrounds. Participants were submitted to a protocol of established neuropsychological tests that were selected to assess the central executive, phonological loop, and visuospatial sketchpad. The results revealed that these factors influenced working memory abilities differentially. Education level influenced all the three components in the same direction. Individuals with higher academic qualifications have better performance in tests assessing the central executive, phonological loop, and visuospatial sketchpad, whereas age affected performance in the task evaluating the central executive. Age and gender also influenced the performance in tasks related to visuospatial sketchpad in the sense that younger individuals or men reveal better visual and spatial abilities as conceptualized in the visuospatial sketchpad.
\end{abstract}

Keywords Age $\cdot$ Central executive $\cdot$ Educational level $\cdot$ Gender differences $\cdot$ Phonological loop $\cdot$ Visuospatial sketchpad

\section{Introduction}

The growing interest in working memory is related to the implications that these functions have at the level of other cognitive abilities (Jonides and Smith 1997), such as reasoning and learning abilities (Baddeley et al. 2009).

Several studies report that working memory may differ according to gender (Lejbak et al. 2011), age (Bender and Raz 2012) or educational level (Lam et al. 2013), which motivate a study on the role of these individual differences in working memory components.

One of the most influential studies to the definition of working memory is the Baddeley and Hitch's model of working memory (Baddeley and Hitch 1974), which divided working memory into three components: the central executive and two subcomponents: the phonological loop and the visuospatial sketchpad, being subordinate of the central

\footnotetext{
R. M. Morais

Universidad de Salamanca, Salamanca, Spain

Universidade Lusófona de Humanidades Tecnologias/COPELABS, Lisbon, Portugal

3 1750-157 Lisbon, Portugal
}

executive with functions related to temporal processing of verbal (i.e., phonological loop) and visuospatial information (i.e., visuospatial sketchpad) (Baddeley 2007).

This model evolved with the inclusion of a fourth component: the episodic buffer that serves the central executive acting on the integration of material from the other two subcomponents in close relationship with long-term memory (Baddeley 2000).

The neuroanatomical structures underlying these processes have been studied using functional magnetic resonance imaging (fMRI), in which evidence suggests a link between activation of the dorsolateral prefrontal brain area and task performance involving the central executive (Blumenfeld et al. 2011).

The areas related to the central executive are located, but not limited to the prefrontal cortex (Baddeley 2011). Increased activations were found in the left cerebellum hemisphere for verbal tasks and in the right cerebellum hemisphere for non-verbal tasks (Stoodley et al. 2012).

The neural substrates underlying the phonological loop have also been demonstrated. Awh et al. (1996) in a PET study found that when a participant performed a verbal letter recall task, different brain areas were activated: Brodmann areas (BA) 7 and BA 40 in left hemisphere, as well as BA 6 and BA 44 in the left hemisphere, the anterior cingulate and 
the right cerebellum (Marvel and Desmond 2012), whereas those associated with the processes of the visuospatial sketchpad are located in the right occipital lobe (BA 19), the right temporoparietal region (BA 7 and BA 40), the premotor area (BA 6), in the lower right prefrontal lobe (BA 47) (Baddeley 2007) and left cerebellum (Chanraud et al. 2011).

Due to brain aging and the progressive loss of neural tissue, age is often associated with decline in working memory processing (Schulze et al. 2011). However, these effects are more pronounced in complex tasks involving the manipulation of material rather than in memory capacity solely (Kemper et al. 2013). Therefore, as people age, the performance in working memory tasks that require a degree of mental manipulation of the material will be increasingly difficult as in the case of recalling a list of digits backwards (Mastroianni et al. 1996), reading span ability (Meguro et al. 2000), or performance in the n-back test (Schmiedek et al. 2009).

However, the effects of age are less clear in the phonological loop, both for studies with sentence span (Craik et al. 1990) and digit or word span (Bireta et al. 2013) that have not revealed age effects. There is also evidence of age effects on the visuospatial sketchpad (Coates et al. 1999; Rodriguez et al. 2001; Luo et al. 2013).

The educational level has been also associated with the central executive (Tun and Lachman 2008; Roldán-Tapia et al. 2012). Education can have a positive effect on general neuropsychological performance (Lam et al. 2013), and on tasks that assess the phonological loop, the visuospatial sketchpad and central executive (Silva et al. 2012). An earlier study by Ardila et al. (2000) revealed that performance in backward digit-span tasks was also sensitive to the educational level.

However, the results are not consistent for the effects of gender on working memory. A systematic review of the literature on gender differences in working memory has suggested that there were no significant gender differences in the performance of the WAIS subtests (Torres et al. 2006). A study reported gender differences only for the visuospatial sketchpad that was the only component in which men performed better than women when assessed with the n-back test (Lejbak et al. 2011).

The studies previously reported are diverse in the sense that the same were conducted in different samples and under distinct methods. Therefore, to provide a more comprehensive view on the potential effects of individual variables on working memory, it is important to study the contributions in a large sample of healthy individuals. In this study, the main goal was to explore the roles of potential confounders such as gender, age and education on working memory abilities. We expected differential effects of age and education on the central executive. We hypothesized that older persons would have poorer ability in this component, whereas higher education would be associated with better ability in the central executive, which was assessed by the backwards digit span subtest of the WAIS and the reading span test. As regards to the phonological loop, we expected only a positive effect of education on this ability as assessed with the forward digit span subtest of the WAIS. As for the visual-spatial component, we expected an effect of age (negative), education (positive) as well as for men both for the Visual Patterns Test and the Corsi Block-tapping Test.

\section{Method}

\section{Participants}

Three hundred and two adults between the ages of 18 and 65 were recruited from the general population. These participants were recruited from a university campus, and also from different senior universities and employment centres in Lisbon region. All participants had Portuguese nationality. The exclusion criteria were as follows: (1) clinical history of mental or neurological disorder; (2) cognitive impairment as assessed with the Mini-Mental State Examination-MMSE (Folstein et al. 1975): participants were excluded for scores below: (a) 16 for illiterate persons, (b) 23 for schooling between 1 and 11 years, (c) 28 for schooling above 11 years, according to the cut-offs for the Portuguese population (Guerreiro et al. 1994); and (3) the Short Test (Kokmen et al. 1987): participants were excluded for scores below: (a) 32 for people aged between 26 and 49 years old, (b) 31 for ages between 50 and 59 years old, (c) 30 for ages between 60 and 69 years old; (3) as well as prior or current use of alcohol or psychoactive substances.

Sixty participants were excluded due to these criteria: 41 participants ( 24 men and 17 women) scored below than expected for a normative sample in the MMSE and the Short Test; 12 participants ( 7 men and 5 women) had clinical history of mental and neurological disorders; 7 participants (5 men and 2 women) had history of alcohol consumption and/ or other psychoactive substances.

Therefore, the final sample for this study comprised 302 individuals (153 women and 149 men). The average age of this sample is 34 years old ( $S D=15$ years). Women are slightly older than men $(M=36 \pm 14$ years for women vs. $M=33 \pm 15$ years for men).

\section{Measures}

The cognitive screening was conducted with the Mini-Mental State Examination (Folstein et al. 1975), which is adapted to the Portuguese population by Guerreiro et al. (1994), and the Short Test (Kokmen et al. 1987).

Working memory was assessed under the model of Baddeley and Hitch (1974) considering the underlying 
components of working memory: central executive, phonological loop and the visuospatial sketchpad. As for the central executive, this component was assessed through the backward digit-span subtest from the Wechsler Adult Intelligence Scale-WAIS (Wechsler 1997); and the Reading Span Test (Daneman and Carpenter 1980). The phonological loop was evaluated with the forward digit-span from the WAIS (Wechsler 1997), whereas the visuospatial sketchpad was assessed for both the visual and spatial dimensions: the Visual Patterns Test-VPT (Della Sala et al. 1999) for the visual and the Corsi Block-tapping Test (Milner 1971) for the spatial dimension of working memory.

\section{Procedure}

The neuropsychological assessment took place in regular and senior universities and in employment centres in the Lisbon region. After obtaining authorization from these institutions, the individuals were approached and asked to collaborate in the study. The purpose of the study was explained and a written informed consent was collected from individuals who were interested in participating in the investigation. After this informed consent, the participants were asked about prior medical conditions and sociodemographic data. Following the anamnesis, the screening measures and the neuropsychological instruments assessing working memory were completed individually in a quiet room that was set for this specific purpose on each of the institutions where the sample was recruited. The neuropsychological assessment was conducted by the authors involved in this study in one session that took approximately $45 \mathrm{~min}$.

\section{Statistical Analysis}

The statistical analysis was conducted separately for each component of working memory. These analyses were performed in two steps. In the first place, the descriptive statistics were calculated for each component to show the average scores and variability according to the groups that were being studied. Second, linear regression analyses using stepwise extraction method were conducted to determine the best predictors of performance on each of the three components of working memory. The independent variables entered in the linear regressions were the individual variables concerning age, gender and education. The assumptions of linear regression analysis were also tested and were found to be valid for the dependent variables, namely in what concerns to multivariate normality and absence of multicollinearity. The dependent variables were: (1) the score from backward digit-span subtest-WAIS and the total score in Reading Span Test (central executive); (2) the total score from the forward digit-span subtest-WAIS (phonological loop); and (3) the total score in the Visual Patterns Test (visual sketchpad) and total score in the Corsi Block-tapping Test (spatial sketchpad).

\section{Results}

The descriptive statistics for each of the subtests assessing working memory abilities are presented in Table 1 . The results from the linear regression analyses on each component of working memory are depicted in Table 2. Table 3 describes the standardized Beta effects of the predictors on each of the dependent variables.

\section{Central Executive: Backward Digit-Span}

The linear regression analysis was conducted with the total score from the backward digit-span task as dependent variable and age, gender and education level as independent variables. The results showed that only education level was considered as a significant predictor of neuropsychological performance on the backward digit-span task $(F(1,300)=52.818 p<.001)$. The final regression model explained $15 \%$ of the variance in the dependent variable.

\section{Central Executive: Reading Span Test}

The same regression analysis was performed but with the total score from the Reading Span Test as dependent variable, which included education level and age as significant predictors of the dependent variable $(p<.05)$. The education level was extracted in the first step of the analysis, explaining $15.7 \%$ of the total variance $(F(1,300)=55.940$; $p<.001)$, whereas age was extracted in the second step $(F(2$, $299)=38.363 ; p<.001)$, explaining $4.7 \%$. The full model explained $20.4 \%$ of the total variance of the performance on the Reading Span Test.

\section{Phonological Loop: Forward Digit-Span}

The same analysis was carried out to identify the predictors of performance in Forward Digit-Span task. The

Table 1 Descriptive statistics for the neuropsychological tests

\begin{tabular}{llcll}
\hline & Min & Max & $M$ & $S D$ \\
\hline Central executive (BDS) & 2 & 8 & 5.04 & 1.13 \\
Central executive (RST) & 2 & 5 & 3.04 & 0.70 \\
Phonological loop (FDS) & 4 & 9 & 7.50 & 1.10 \\
Visual sketchpad (VPT) & 4 & 15 & 8.82 & 1.98 \\
Spatial sketchpad (CBT) & 3 & 7 & 4.91 & 0.84 \\
\hline
\end{tabular}

$B D S$ backward digit-span, $R S T$ reading span test, $F D S$ forward digitspan, $V P T$ visual patterns test, $C B T$ Corsi block-tapping test 
Table 2 Regression scores for significant models

\begin{tabular}{lllllll}
\hline Domain & DV & Predictors & $R$ & $R^{2}$ & $\Delta \mathrm{R}^{2}$ & $F$ \\
\hline Central executive & BDS & EL & .387 & .150 & - & $52.818^{* * *}$ \\
& RST & EL+Age & .452 & .204 & .047 & $38.363^{* * *}$ \\
Phonological loop & FDS & EL & .245 & .060 & - & $19.178^{* * *}$ \\
Visuospatial sketchpad & VPT & Age+EL+Gender & .555 & .308 & $.069^{\mathrm{a}}$ & $44.223^{* * *}$ \\
& CBT & Age + Gender+EL & .478 & .228 & $.066^{\mathrm{b}}$ & $29.365^{* * *}$ \\
\hline
\end{tabular}

$B D S$ backward digit-span, $R S T$ reading span test, $F D S$ forward digit-span, VPT visual patterns test, $C B T$ Corsi block-tapping test, $E L$ education level

$* * * p<.001$

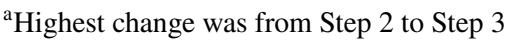

${ }^{\mathrm{b}}$ Lowest change was from Step 1 to Step 2
Table 3 Beta scores for each predictor included in the model

\begin{tabular}{llllr}
\hline Domain & DV & Predictors & \multicolumn{2}{l}{$t$} \\
\hline Central executive & BDS & EL & .387 & $7.268 * * *$ \\
& RST & EL & .361 & $6.905 * * *$ \\
& & Age & -.220 & $-4.204 * * *$ \\
Phonological loop & FDS & EL & .245 & $4.379 * * *$ \\
Visuospatial sketchpad & VPT & Age & -.351 & $-7.153 * * *$ \\
& & EL & .293 & $5.927 * * *$ \\
& & Gender & .266 & $5.441 * * *$ \\
& CBT & Age & -.248 & $-4.775 * * *$ \\
& & Gender & .297 & $5.752 * * *$ \\
& & EL & .257 & $4.927 * * *$ \\
\hline
\end{tabular}

$B D S$ backward digit-span, $R S T$ reading span test, $F D S$ forward digitspan, $V P T$ visual patterns test, $C B T$ Corsi block-tapping test, $E L$ education level

$* * * p<.001$

results revealed that only education level was considered as a significant predictor of this task $(F(1,300)=19.178$; $p<.001)$, which explained $6 \%$ of the total variance.

\section{Visual Sketchpad: Visual Patterns Test}

The linear regression analysis for the VPT as dependent variable showed that age, education and gender were all significant predictors of performance in this test. The variable concerning age was the first variable extracted in the analysis $(F(1,300)=64.808 ; p<.001)$ that determined $17.8 \%$ of the total variance, followed by education level $(F(2,299)=47.035 ; p<.001)$ and gender $(F(3$, $298)=44.223 ; p<.001)$. Education level and gender explained 6.1 and $6.9 \%$ of the total variance, respectively. The full regression model with three predictors explained $30.8 \%$ of performance in the VPT.

\section{Spatial Sketchpad: Corsi Block-Tapping Test}

The same analysis but for the Corsi Block-tapping Test revealed that all three variables entered in the analysis were found to be significant predictors. The first variable extracted was age $(F(1,300)=32.989 ; p<.001)$, followed by gender $(F(2,299)=29.604 ; p<.001)$ and education level $(F(3,298)=29.365 ; p<.001)$. Age explained $9.9 \%$ of the variance, whereas education and gender explained similar proportions, 6.6 and $6.3 \%$, respectively. The full model explained $22.8 \%$ of performance in the Corsi Block-tapping Test.

\section{Discussion}

The aim of the study was to investigate whether individual differences related to age, gender and education influence working memory. We expected that these results could contribute to a better understanding of working memory abilities in healthy individuals.

The components of working memory were tested according to the classical model of working memory from Baddeley and Hitch (1974).

Concerning the central executive, the obtained results suggested positive effects of education on this component. Individuals with higher education levels revealed better performance on the tasks evaluating the central executive, such as backward digit-span and RST, which concur with a previous literature (Ardila et al. 2000; Lehto 1995). One possible explanation for these results is related to the concept of cognitive reserve that may be associated with increase in the volume of gray matter in the frontal and parietal lobes (Bartrés-Faz et al. 2009), while improving information processing from the central executive (Roldán-Tapia et al. 2012).

Age has been consistently associated with performance of tasks assessing the central executive (Kemper et al. 2013), as in backward digit-span tasks (Roldán-Tapia et al. 2012), reading span (Blair et al. 2011) and $n$-back tasks 
(Schmiedek et al. 2009). However, in the current study, these results were supported only for RST, but not for backward digit-span. Age differences cohort between our study and those previous studies that included participants older than 65 years old may explain such discrepancies (Gregoire and Van der Linden 1997). No effects of gender were observed in the central executive. Gender effects were also negligible in the central executive as observed by Robert and Savoie (2006).

On the one hand, in the phonological loop, only education level explained performance in the forward digit-span task with a higher level of education predicting better performance in this task. These results are consistent with those obtained by other studies (e.g., Silva et al. 2012). Education may create a set of cognitive strategies that may help improving cognitive abilities (Scribner and Cole 1981). On the other hand, age did not affect performance in tasks from the phonological loop. The results concerning age have been inconsistent. For instance, Bireta et al. (2013) did not find age effects on the digit span, whereas Ostrosky-Solis et al. (1998) did find decrease in the performance of the digit span task with age. However, there are also suggestions that the effects of age may be more pronounced in older individuals (Gregoire and Van Der Linden 1997), which may explain the lack of associations with age in our study. No associations with gender were also found, which is in agreement with a previous literature (Robert and Savoie 2006).

In contrast, age, gender and education explained performance in tasks from the visuospatial sketchpad. The results suggest that younger individuals, those with higher education level, or men have better performance in the tasks involving the visuospatial sketchpad. Beigneux et al. (2007) reported the same pattern of results for age both in the Corsi Block-tapping Test and the Visual Patterns Test. Brown et al. (2012) claim that the decrease in performance evidenced in these tasks with increasing age is essentially due to decline in processing speed ability.

As for education, while there are studies suggesting effects of schooling on working memory (e.g., Gropper and Tannock 2009), others seem to contradict such results (e.g., Cavallini et al. 2009). Moreover, the associations with gender have also been reported previously (Lejbak et al. 2011). According to Herrnstein and Murray (1994), the prediction that men show better performance than women in visuospatial tasks may be related to biological and social aspects, being dependent on hormonal changes that occur at birth and through adolescence, but also due to genetic factors that result from differences in the phylogenetic evolution of men and women. Ancient men due to hunting may have developed their visuospatial abilities more than women that had different roles (Kolb and Whishaw 1990). As regards to social aspects, men may be also more involved in visuospatial tasks during their lives (Lawton and Morrin 1999).
In sum, these findings yield the notion that performance on tasks assessing different components of working memory in the classical view of Baddeley and Hitch (1974), may vary depending on individual characteristics of education level, age, or gender. The central executive may be determined by education and age, with better cognitive ability for younger people or individuals with higher levels of education. The phonological loop may be determined by education, with better performance for individuals with higher levels of education, whereas the visuospatial sketchpad depends on the former but also on gender, with men yielding better neuropsychological performance in visual and spatial tasks. Although this study involves a large sample of adult participants, it would be interesting to include a cohort of elderly participants in future research, since these outcomes may be more evident in older age cohorts. It would have also been important to explore the abilities associated with the central executive with the $N$-back task, which could have provided other insights to explain the findings from this study.

The overall results indicate that age, education, but also gender may be important confounders of performance in neuropsychological tests evaluating working memory abilities. This investigation contributes also to the study of working memory in adult population up to the age of retirement, which allow also to understand how these abilities change in the economically active population.

\section{References}

Ardila, A., Ostrosky-Solis, F., Rosselli, M., \& Gómez, C. (2000). Age-related cognitive decline during normal aging: The complex effect of education. Archives of Clinical Neuropsychology, 15(6), 495-513. https://doi.org/10.1016/S0887-6177(99)00040-2.

Awh, E., Jonides, J., Smith, E. E., Schumacher, E. H., Koeppe, R. A., \& Katz, S. (1996). Dissociation of storage and retrieval in verbal working memory: Evidence from positron emission tomography. In A. Baddeley (Ed.), Working memory, thought, and action (pp. 211-234). Oxford: University Press.

Baddeley, A. (2000). The episodic buffer: A new component of working memory? Trends in Cognitive Sciences, 4(11), 417-423. https ://doi.org/10.1016/S1364-6613(00)01538-2.

Baddeley, A. (2007). Working memory, thought, and action. Oxford: University Press.

Baddeley, A. (2011). The memory man. The Psychologist, 24(5), 354-355.

Baddeley, A. D., Eysenck, M. W., \& Anderson, M. C. (2009). Memory. Hove: Psychology Press.

Baddeley, A. D., \& Hitch, G. J. (1974). Working memory. In G. H. Bower (Ed.), The psychology of learning and motivation (Vol. 8, pp. 47-90). New York: Academic Press.

Bartrés-Faz, D., Solé-Padullés, C., Junqué, C., Rami, L., Bosch, B., Bargalló, N., Falcón, C., Sánchez-Valle, R., \& Molinuevo, J. L. (2009). Interactions of cognitive reserve with regional brain anatomy and brain function during a working memory task in healthy elders. Biological Psychology, 80(2), 256-259. https:// doi.org/10.1016/j.biopsycho.2008.10.005. 
Beigneux, K., Plaie, T., \& Isingrini, M. (2007). Aging effects on visual and spatial components of working memory. Aging and Human Development, 65(4), 301-314. https://doi.org/10.2190/AG.65.4.b.

Bender, A., \& Raz, N. (2012). Age-related differences in recognition memory for items and associations: Contribution of individual differences in working memory and metamemory. Psychology and Aging, 27(3), 691-700. https://doi.org/10.1037/a0026714.

Bireta, T. J., Fine, H. C., \& VanWormer, L. A. (2013). Does working memory change with age? The interactions of concurrent articulation with the effects of word length and acoustic confusion. Aging, Neuropsychology, and Cognition, 20(2), 125-147. https ://doi.org/10.1080/13825585.2012.657607.

Blair, M., Vadaga, K., Shuchat, J., \& Li, K. (2011). The role of age and inhibitory efficiency in working memory processing and storage components. The Quarterly Journal of Experimental Psychology, 64(6), 1157-1172. https://doi.org/10.1080/17470218.2010.54067 0 .

Blumenfeld, R. S., Parks, C. M., Yonelinas, A. P., \& Ranganath, C. (2011). Putting the pieces together: The role of dorsolateral prefrontal cortex in relational memory encoding. Journal of Cognitive Neuroscience, 23(1), 257-265. https://doi.org/10.1162/ jocn.2010.21459.

Brown, L., Brockmole, J., Gow, A., \& Deary, I. (2012). Processing speed and visuospatial executive function predict visual working memory ability in older adults. Experimental Aging Research, 38(1), 1-19. https://doi.org/10.1080/0361073X.2012.636722.

Cavallini, E., Cornoldi, C., \& Vecchi, T. (2009). The effects of age and professional expertise on working memory performance. Applied Cognitive Psychology, 23, 382-395. https://doi.org/10.1002/ acp.1467.

Chanraud, S., Pitel, A., Pfefferbaum, A., \& Sullivan, E. (2011). Disruption of functional connectivity of the default-mode network in alcoholism. Cerebral Cortex, 21(10), 2272-2281. https://doi. org/10.1093/cercor/bhq297.

Coates, R., Sanderson, K., Hamilton, C. J., \& Heffernan, T. (1999). Identifying differential processes in visuo-spatial working memory. Proceedings of The British Psychological Society, 7, 38.

Craik, F. I. M., Morris, R. G., \& Gick, M. L. (1990). Adult age differences in working memory. In G. Vallar \& T. Shallice (Eds.), Neuropsychological impairments of short-term memory (pp. 247267). New York: Cambridge University Press.

Daneman, M., \& Carpenter, P. A. (1980). Individual differences in working memory and reading. Journal of Verbal Learning and Verbal Behavior, 19, 450-466. https://doi.org/10.1016/S0022 -5371(80)90312-6.

Della Sala, S., Gray, C., Baddeley, A. D., Allamano, N., \& Wilson, L. (1999). Pattern span a tool for unwelding visuo-spatial memory. Neuropsychología, 37, 1189-1199. https://doi.org/10.1016/S0028 -3932(98)00159-6.

Folstein, M. F., Folstein, S. E., \& McHungh, P. R. (1975). A practical method for grading the cognitive state of patients for the clinician. Journal of Psychiatric Research, 12, 189-198. https://doi. org/10.1016/0022-3956(75)90026-6.

Gregoire, J., \& Van der Linden, M. (1997). Effects of age on forward and backward digit spans. Aging, Neuropsychology and Cognition, 4, 140-149. https://doi.org/10.1080/13825589708256642.

Gropper, R., \& Tannock, R. (2009). A pilot study of working memory and academic achievement in college students with ADHD. Journal of Attention Disorders, 12(6), 574-581. https://doi. org/10.1177/1087054708320390.

Guerreiro, M., Silva, A. P., Botelho, M. A., Leitão, O., Castro-Caldas, A., \& Garcia, C. (1994). Adaptação à população portuguesa na tradução do "MiniMental State Examination" (MMSE). Revista Portuguesa de Neurologia, 1, 9.

Herrnstein, R. J., \& Murray, C. A. (1994). The bell curve: Intelligence and class structure in American life. New York: Free Press.
Jonides, J., \& Smith, E. (1997). Cognitive neuroscience. Hove: Psychology Press.

Kemper, S., Bontempo, D., Schmalzried, R., Mckedy, W., Tagliaferri, B., \& Kieweg, D. (2013). Tracking reading: Dual task costs of oral reading for young versus older adults. Journal of Psycholinguistic Research. https://doi.org/10.1007/s10936-013-9240-z.

Kokmen, E., Naessens, J. M., \& Offotd, K. P. (1987). A short test of mental status: Descriptions and preliminary results. Clinical Proceedings, 62, 281-288. https://doi.org/10.1016/S0025 -6196(12)61905-3.

Kolb, B., \& Whishaw, I. Q. (1990). Fundamentals of human neuropsychology. Cambridge: Academic Press.

Lam, M., Eng, G., Raspisarda, A., Subramaniam, M., Kraus, M., Keefe, R., \& Collinson, S. (2013). Formulation of the age-education index: Measuring age and education effects in neuropsychological performance. Psychological Assessment, 25(1), 61-70. https ://doi.org/10.1037/a0030548.

Lawton, C. A., \& Morrin, K. A. (1999). Gender differences in pointing accuracy in computer simulated 3D mazes. Sex Roles, 40(1-2), 73-92. https://doi.org/10.1023/A:1018830401088.

Lehto, J. (1995). Working memory and school achievement in the ninth form. Educational Psychology, 15(3), 271-281. https://doi. org/10.1080/0144341950150304.

Lejbak, L., Crossley, M., \& Vrbancic, M. (2011). A male advantage for spatial and object but not verbal working memory using the n-back task. Brain and Cognition, 76(1), 191-196.

Luo, L., Craik, F., Moreno, S., \& Bialystok, E. (2013). Bilingualism interacts with domain in a working memory task: Evidence from aging. Psychology and Aging, 28(1), 28-34. https://doi. org/10.1037/a0030875.

Marvel, C. L., \& y Desmond, J. E. (2012). From storage to manipulation: How the neural correlates of verbal working memory reflect varying demands on inner speech. Brain and Language, 120(1), 42-51. https://doi.org/10.1016/j.bandl.2011.08.005.

Mastroianni, F., Panza, F., Solfrizzi, V., Nardó, G., Torres, F., Resta, F., \& Capurso, A. (1996). Analysis of same aspects of learning and memorization proceses in an adult population. Archives of Gerontology and Geriatrics, 5, 29-34. https://doi.org/10.1016/01674943(96)86908-1.

Meguro, Y., Fujii, T., Yamadori, A., Tsukiura, T., Suzuki, K., Okuda, J., \& Osaka, M. (2000). The nature of age-related decline on the reading span task. Journal of Clinical and Experimental Neuropsychology, 22(3), 391-398. https://doi.org/10.1076/13803395(200006)22:3;1-V;FT391.

Milner, B. (1971). Interhemispheric differences in the localization of psychological processes in man. British Medical Bulletin, 27, 272-277.

Psychological Corporation (1997). WAIS III-WMS III technical manual. San Antonio: Harcourt Brace \& Company.

Robert, M., \& Savoie, N. (2006). Are there gender differences in verbal and visuospatial working-memory resources? European Journal of Cognitive Psychology, 18(3), 378-397. https://doi. org/10.1080/09541440500234104.

Rodriguez, M. A., Ladera, V., \& Perea, M. V. (2001). Normative value in visual-mnesic task in normal adult subjects. International Conference on Memory. Valencia. July 16-20. In Rodriguez, M. A. (2003). Estudio de los rendimientos mnésicos en sujetos españoles mayores de 65 años. Tesis Doctoral.

Roldán-Tapia, L., García, J., \& León, I. (2012). Cognitive reserve, age, and their relation to attentional and executive functions. Applied Neuropsychology, 19(1), 2-8. https://doi.org/10.1080/09084 282.2011.595458

Schmiedek, F., Li, S., \& Lindenberger, U. (2009). Interference and facilitation in spatial working memory: Age-associated differences in lure effects in the n-back paradigm. Psychology and Aging, 24(1), 203-210. https://doi.org/10.1037/a0014685. 
Schulze, E. T., Geary, E. K., Susmaras, T. M., Paliga, J. T., Maki, P. M., $\&$ Little, D. M. (2011). Anatomical correlates of age-related working memory declines. Journal of Aging Research, 2011, 606871.

Scribner, S., \& Cole, M. (1981). The psychology of literacy. Cambridge: Harvard University Press.

Silva, C., Faísca, L., Ingvar, M., Petersson, K., \& Reis, A. (2012). Literacy: Exploring working memory systems. Journal of Clinical and Experimental Neuropsychology, 34(4), 369-377. https://doi. org/10.1080/13803395.2011.645017.

Stoodley, C. J., Valera, E. M., \& Schmahmann, J. D. (2012). Functional topography of the cerebellum for motor and cognitive tasks: An fMRI study. Neuroimage, 59(2), 1560-1570. https:// doi.org/10.1016/j.neuroimage.2011.08.065.

Torres, A., Gómez-Gil, E., Vidal, A., Puig, O., Boget, T., \& Salamero, M. (2006). Diferencias de género en las funciones cognitivas e influencia de las hormonas sexuales. Actas Españolas de Psiquiatría, 34(6), 408-415.

Tun, P. A., \& Lachman, M. E. (2008). Age differences in reaction time and attention in a national telephone sample of adults: Education, sex, and task complexity matter. Developmental Psychology, 44(5), 1421-1429. https://doi.org/10.1037/a0012845. 